\title{
Exhaled carbon monoxide as a marker for evaluating smoking abstinence in a Brazilian population sample
}

\author{
Jose Chatkin*, Leandro Fritscher, Carolina de Abreu, \\ Daniela Cavalet-Blanco, Gustavo Chatkin, Mario Wagner, \\ Carlos Fritscher
}

Department of Pulmonary Diseases, Hospital São Lucas, Pontificia Universidade Católica do Rio Grande do Sul (PUCRS), Brazil

Received 16 August 2006; accepted 31 October 2006

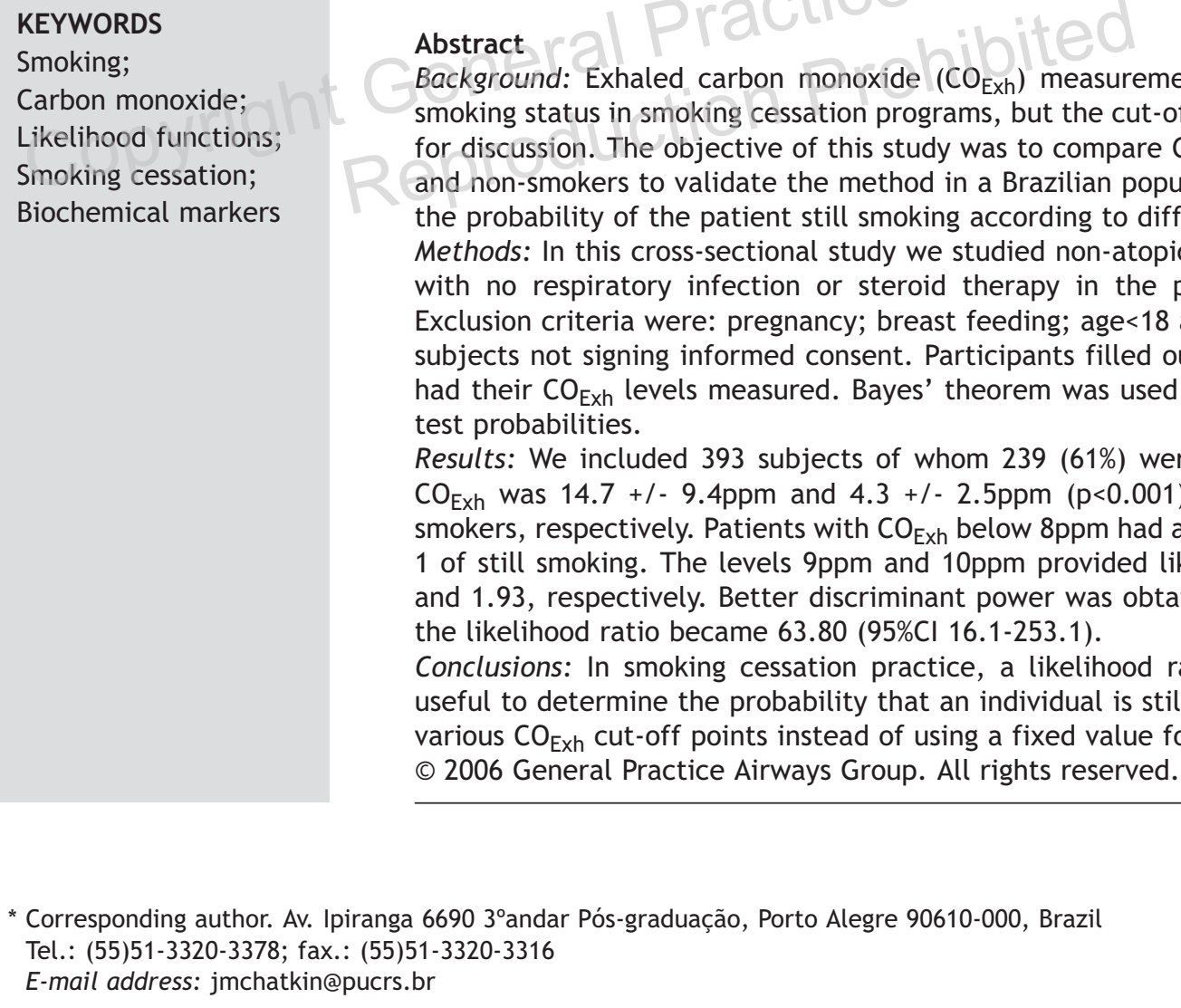

\section{Abstract} test probabilities. the likelihood ratio became $63.80(95 \% \mathrm{Cl} 16.1-253.1)$.

๑) 2006 General Practice Airways Group. All rights reserved.

\footnotetext{
* Corresponding author. Av. Ipiranga $66903^{\circ}$ andar Pós-graduação, Porto Alegre 90610-000, Brazil Tel.: (55)51-3320-3378; fax.: (55)51-3320-3316

E-mail address: jmchatkin@pucrs.br
}

Background: Exhaled carbon monoxide $\left(\mathrm{CO}_{\text {Exh }}\right)$ measurement is used to confirm smoking status in smoking cessation programs, but the cut-off level is still a matter for discussion. The objective of this study was to compare $\mathrm{CO}_{\mathrm{Exh}}$ levels in smokers and non-smokers to validate the method in a Brazilian population and to estimate the probability of the patient still smoking according to different cut-off points. Methods: In this cross-sectional study we studied non-atopic Caucasian volunteers with no respiratory infection or steroid therapy in the preceding four weeks. Exclusion criteria were: pregnancy; breast feeding; age $<18$ and $>65$ years old; and subjects not signing informed consent. Participants filled out a questionnaire and had their $\mathrm{CO}_{\text {Exh }}$ levels measured. Bayes' theorem was used to calculate the post-

Results: We included 393 subjects of whom $239(61 \%)$ were smokers. The mean $\mathrm{CO}_{\text {Exh }}$ was $14.7+/-9.4 \mathrm{ppm}$ and $4.3+/-2.5 \mathrm{ppm}(\mathrm{p}<0.001)$ in smokers and nonsmokers, respectively. Patients with $\mathrm{CO}_{\text {Exh }}$ below $8 \mathrm{ppm}$ had a likelihood ratio below 1 of still smoking. The levels $9 \mathrm{ppm}$ and 10ppm provided likelihood ratios of 1.50 and 1.93 , respectively. Better discriminant power was obtained at $>11 \mathrm{ppm}$, when

Conclusions: In smoking cessation practice, a likelihood ratio approach may be useful to determine the probability that an individual is still smoking according to various $\mathrm{CO}_{\text {Exh }}$ cut-off points instead of using a fixed value for all patients. 


\section{Introduction}

Smoking is the most widespread addiction, affecting about one third of the world's population. ${ }^{.}$In Brazil, the situation is of some concern, ${ }^{2-5}$ given that each year about 200,000 Brazilians die early because of smoking. 4,5

Stopping smoking is only achieved by $6 \%$ of smokers who try to quit without medical help. ${ }^{6}$ Professional input in the form of cognitive behaviour therapy and specific pharmacotherapy helps to achieve higher success rates. ${ }^{3,7}$

However, abstinence during smoking cessation treatment needs to be confirmed by objective measurements since it is known that smokers sometimes provide false information about their smoking status. This happens especially if the individual is under pressure to quit and therefore is biased towards producing a socially desirable response when questioned. ${ }^{8}$ The prevalence of patients who state that they are not smoking when they actually still are varies between 3 and $10 \%$. Lower incidences of unreliable reporting are found in general population surveys while higher proportions are found in patients enrolled in quitsmoking programs. ${ }^{9 \cdot 11}$

To avoid these biases, biochemical markers for abstinence have been introduced in clinical practice. Carbon monoxide level in exhaled air $\left(\mathrm{CO}_{\text {Exh }}\right)$ is the most often used. ${ }^{12}$ It is an affordable marker measured by a non-invasive technique which provides immediate and reliable results. ${ }^{13}$ It has been used in various centres in Brazil, ${ }^{14-16}$ although its use has not been widely validated in this country.

The aim of this study was to compare the levels of $\mathrm{CO}_{\text {Exh }}$ in smokers and non-smokers in a sample of the Brazilian population. In addition, given the importance for the clinician of ascertaining whether or not the patient enrolled in a quitsmoking program is still smoking, we decided to estimate likelihood ratios for smoking at different levels of $\mathrm{CO}_{\mathrm{Exh}}$.

\section{Material and methods}

Two groups of individuals were selected to be included in this cross-sectional study. The first group constituted smokers appearing for their first visit to our outpatient clinic for smoking cessation. The second group constituted individuals recruited among shoppers in a local shopping mall who declared themselves to be non-smokers, stated that they were in good health, and did not consider themselves as passive smokers. Since in both situations there was no pressure involved, we assumed that subjects had no reasons to hide their smoking status or to give false information. Volunteers were non-atopic Caucasians without any respiratory infections who had not received corticosteroids in the preceding four weeks. An informed consent form was signed before enrolment. Exclusion criteria were: pregnancy; breast feeding; age less than 18 or greater than 65 years; passive smokers; and subjects with a previous diagnosis of COPD or any other pulmonary disease. Participants filled out a standard questionnaire regarding demographic information, smoking habits (number of cigarettes per day, total years of smoking) and Fagerstrom test of nicotine dependence-FTND.

$\mathrm{CO}_{\text {Exh }}$ was measured by a MicroCO Meter (MicroCO - Micro Medical Ltd, Rochester, Kent, $U K)$, using an electrochemical sensor. Patients were instructed to breathe deeply and to hold their breath for 20 seconds and then to exhale slowly and completely through a mouthpiece. Smokers had their $\mathrm{CO}_{\text {Exh }}$ measured at no more than two hours since the last smoked cigarette. The coefficient of variation of these measurements was accepted if within 5 and $10 \%$. Subjects also had their weight and height measured.

$\mathrm{CO}_{\text {Exh }}$ levels and age of volunteers were analysed by Student's t-test for independent samples. Spearman's correlation was utilised to determine the correlation between $\mathrm{CO}_{\text {Exh }}$ with number of cigarettes smoked and also with time since last cigarette smoked (alpha $=0.05$ ).

Measures of diagnostic performance were based on likelihood ratios (LR). This approach was used to estimate the ratio of the probability of a particular level of $\mathrm{CO}_{\text {Exh }}$ observed in a smoking patient compared to the same probability in a non-smoker. LRs above 10 and below 0.1 were used as strong evidence to rule in or rule out, respectively, the smoking status of the participants. ${ }^{17}$ Area under the ROC curve was obtained with $95 \% \mathrm{Cl}$, considering several cut off points. Statistical procedures were conducted using SPSS 12.0 (SPSS Inc, Chicago, IL, USA).

Ethical approval for the study was obtained from the institutional ethics board (PUCRS Ethics Committee). All participants provided written informed consent before inclusion in the protocol.

\section{Results}

A total of 393 individuals were included, 239 (61\%) being smokers. The mean age $( \pm$ SD) was 26.6 ( \pm 9.7$)$ and $28.9( \pm 11.5)$ years among non-smokers and smokers, respectively $(p>0.05)$. The demographic characteristics were similar between 
Table 1 Characteristics of the sample

\begin{tabular}{|c|c|c|c|}
\hline Characteristic & $\begin{array}{c}\text { Smokers } \\
n=154\end{array}$ & $\begin{array}{c}\text { Non-smokers } \\
n=239\end{array}$ & $p$ value \\
\hline \multicolumn{4}{|l|}{ Demographic } \\
\hline Female gender $(\%)$ & 39.2 & 60.8 & 0.21 \\
\hline Age, years; mean+SD & $28.9 \pm 11.5$ & $26.6 \pm 9.7$ & 0.07 \\
\hline Schooling (\%) & & & 0.19 \\
\hline Elementary & 35.1 & 37.8 & \\
\hline High School & 24.5 & 22.7 & \\
\hline University & 40.4 & 39.5 & \\
\hline Exhaled CO (median;P25-P75) & $19(13-26)$ & $4(3-5.3)$ & $<0.001$ \\
\hline \multicolumn{4}{|l|}{ Smoking behavior } \\
\hline Cigarettes/day (mean+SD) & $25.3 \pm 4.5$ & - & \\
\hline Years smoked (mean+SD) & $10.2 \pm 3.8$ & - & \\
\hline \multicolumn{4}{|l|}{ Fagerstrom Dependence (\%) } \\
\hline Mild & 26 & - & \\
\hline Moderate & 50 & - & \\
\hline Severe & 23 & - & \\
\hline
\end{tabular}

Table 2 Estimates of likelihood ratios for different cut-off points of exhaled CO levels in predicting smoking status

\begin{tabular}{ccccc}
\hline $\begin{array}{c}\text { Cut-off } \\
(\mathrm{ppm})\end{array}$ & $\begin{array}{c}\text { Smokers } \\
(\mathrm{n}=239)\end{array}$ & $\begin{array}{c}\text { Non-smokers } \\
(\mathrm{n}=154)\end{array}$ & $\begin{array}{c}\text { Likelihood } \\
\text { ratio (LR) }\end{array}$ & $95 \% \mathrm{Cl}$ \\
$\leq 5$ & 11 & 116 & 0.06 & $0.03-0.11$ \\
6 & 5 & 13 & 0.25 & $0.09-0.68$ \\
7 & 6 & 10 & 0.39 & $0.14-1.04$ \\
8 & 6 & 8 & 0.48 & $0.17-1.37$ \\
9 & 7 & 3 & 1.50 & $0.39-5.73$ \\
10 & 6 & 2 & 1.93 & $0.40-9.46$ \\
$\geq 11$ & 198 & 2 & 63.80 & $16.1-253.1$ \\
\hline
\end{tabular}

ppm = particles per million; area under the receiver operating characteristics curve: $0.96(95 \% \mathrm{Cl} 0.94$ to 0.98$)$

these two groups. The mean $\mathrm{CO}_{\text {Exh }}$ in the group of smokers $(14.7 \pm 9.4 \mathrm{ppm})$ was significantly higher than in non-smokers $(4.3 \pm 2.5 \mathrm{ppm})(\mathrm{p}<0.001)$ and a significant association was found between the quantity of cigarettes smoked per day and the $\mathrm{CO}_{\text {Exh }}$ level $(r=0.7, p<0.001)$ - see Table 1.

Table 2 shows a progressive increase in the likelihood of being a smoker as the $\mathrm{CO}_{\text {Exh }}$ cut-off was progressively set at higher levels. When the value was moved from 10 to $11 \mathrm{ppm}$, a striking gap in the likelihood ratio was observed. The area under the ROC curve was calculated as $0.96(95 \% \mathrm{Cl} 0.94-0.98)$.

\section{Discussion}

In this study, we have shown that a sample of Brazilian smokers have higher $\mathrm{CO}_{\text {Exh }}$ levels than non-smokers and that there is a positive assoc- iation between the number of cigarettes smoked and $\mathrm{CO}_{\text {Exh }}$ level. This is in accordance with the literature. ${ }^{9}$ We also studied $\mathrm{CO}_{\text {Exh }}$ testing as a marker of abstinence, calculating the likelihood ratio for each different level. Using this statistical procedure, we were able to calculate the accuracy of each cut-off point and evaluate how many times more (or less) it predicted the real smoking condition.

Thus, instead of establishing a single cut-off level for all patients - which is the norm in most smoking cessation clinics - a more useful approach seems to be to verify the probability of a person smoking based on the level of exhaled CO. When applied to individuals undergoing treatment in any smoking cessation clinic, this measurement predicts the probability of the patient still smoking even when the patient denies it. Sensitivity, specificity and predictive values do 
not do this, or are dependent on the prevalence of the event (usually unknown), making it difficult to use these parameters in everyday practice. Likelihood ratios could provide a solution by simplifying the real-life evaluation of the patient - especially in primary care.

There is still controversy in the literature regarding which cut-off point for $\mathrm{CO}_{\text {Exh }}$ to use. ${ }^{18} \mathrm{~A}$ reliable level of $\mathrm{CO}$ concentration in exhaled air which can differentiate smokers from non-smokers has not yet been fully established, probably as a consequence of differences in prevalence of misreporting. Thus, while some authors suggest 6 ppm as the most appropriate value, ${ }^{13,16}$ higher $\mathrm{CO}_{\text {Exh }}$ levels, usually equal to or above $10 \mathrm{ppm}$, are the most widely accepted cut-off levels in specialised clinics as the marker for ongoing smoking. . $^{8,19,20}$

In our sample, subjects still smoking a few cigarettes per day, or those who were in the process of quitting but suffering occasional lapses, had a $\mathrm{CO}_{\text {Exh }}$ level lower than $10 \mathrm{ppm}$. These latter patients deserve special consideration because they are at high risk of returning to a heavier smoking lifestyle. In this group, $\mathrm{CO}_{\mathrm{Exh}}$ measurement has a special role, since these are patients whose responses to inquiries regarding smoking behavior are frequently not reliable. Indeed, in such a clinical situation, the interpretation of $\mathrm{CO}_{\mathrm{Exh}}$ results may be not easy, and a categorical classification of a patient as a smoker or non-smoker may be difficult.

Using the likelihood method, patients with a $\mathrm{CO}_{\text {Exh }}$ of $7 \mathrm{ppm}$ had a $0.39(0.14-1.04)$ 'still smoking' probability, even if they denied smoking. When a value of $9 \mathrm{ppm}$ was used, the probability of actually being a smoker became 1.50 (0.395.73). In these groups of individuals, considering that the confidence interval included values below and above 1 , it would be important to utilise complementary methods, albeit more expensive and/or more invasive measures, to determine the clinical situation with more certainty. In the group with $\mathrm{CO}_{\text {Exh }} \geq 11 \mathrm{ppm}$, the probability of an individual still smoking despite stating otherwise was very high, sparing the need for further investigation (LR $63.80,95 \% \mathrm{Cl} 16.1$ to 253.1). Likelihood ratios above 10 are considered to provide strong evidence for ruling out a diagnosis - in this case, the diagnosis of being a 'smoker'. ${ }^{17}$

The strength of this study is that the included patients had no reason to misreport their smoking condition, since they were under no pressure. The main limitation to our conclusions is that in some subgroups the number of individuals was low. Therefore, the conclusions of this study should be considered as preliminary.

We realise that the median $\mathrm{CO}_{\text {Exh }}$ of our non- smokers is higher than expected, but we did not consider this to be of clinical relevance. All shopping malls in Porto Alegre, Brazil, are strictly nonsmoking areas. However, the specific shopping mall where the study was conducted is located in an area of intense traffic activity. The impact of such environmental exposure in our participants is unknown. Also, a faulty heating system cannot be excluded. However, if these potential biases were real, they would have influenced the results of both groups, i.e., smokers and non-smokers.

Based on these preliminary findings, it is possible to speculate that it may be more useful to determine the probability of each individual being a smoker instead of using a categorical classification according to a single value of $\mathrm{CO}_{\text {Exh }}$ for all patients tested. In this way, management of each specific case would be individualised, thereby improving the potential benefits of intervention.

\section{Conflict of interest declaration}

There are no conflicts of interest to declare.

\section{References}

1. Brundtland $\mathrm{GH}$. Achieving worldwide tobacco control. JAMA 2000;284(6):750-1.

2. Chatkin JM, Abreu CM, Haggstram FM, et al. Abstinence rates and predictors of outcome for smoking cessation: Do Brazilian smokers need special strategies? Addiction 2004; 99:778-84.

3. Chatkin JM, Abreu CM, Blanco DC, et al. No gender difference in effectiveness of smoking cessation treatment in a Brazilian real-life setting. Int J Tuberc Lung Dis 2006;10(5):499-503.

4. Costa e Silva V, Koifman S. Smoking in Latin America: a major public health problem. Cad Saude Publica 1998; 14:1-16.

5. Shafey O, Dolwick S, Guindon GE. Smoking prevalence: Brazil. In: Shafey O, Dolwick S, Guindon GE, editors. Tobacco control country profiles. Atlanta, USA: American Cancer Society, 2003:92-93.

6. Low M, Tang JLT. An analysis of the effectiveness of interventions intended to help people stop smoking. Arch Intern Med 1995;155:1933-41.

7. Rigotti N. Treatment of tobacco use and dependence. $N$ Engl J Med 2002;346:506-12.

8. Murray RP, Connett JE, Lauger GG, et al. Error in smoking measures: effects of intervention on relations of cotinine and carbon monoxide to self-reported smoking. The Lung Health Study Research Group. Am J Public Health 1993; 83(9):1251-7.

9. Barrueco M, Jimenes-Ruiz CA, Palomo L, et al. Veracity of smokers' response regarding abstinence at smoking cessation clinics. Arch Bronconeumol 2005;41(3):135-40.

10. Patrick DL, Cheadle A, Thompson DC, et al. The validity of self-reported smoking: a review and metaanalysis. Am J Public Health 1994;84:1086-93. 
11. Rebagliato M. Validation of self reported smoking: editorial. J Epidemiol Commun Health 2002;56:164-5.

12. Ruiz JMG, Barrueco M, Cordovilla $R$ et al. Utilidad de la medida de $\mathrm{CO}$ en aire espirado en el estudio del consumo de tabaco por jóvenes y adolescentes. Rev Clin Esp 1998; 198:440-2.

13. Middleton ET, Morice AH. Breath carbon monoxide as an indication of smoking habit. Chest 2000;117:758-63.

14. Chatkin JM, Abreu CM, Haggstram FM, et al. Exhaled CO: is 10 PPM a reliable threshold value to confirm current smoking? Am J Respir Crit Care Med 2002;165:19s.

15. Laranjeira R, Pillon S, Dunn J. Environmental tobacco smoke exposure among non-smoking waiters: measurement of expired carbon monoxide levels. São Paulo Med J 2000;118:89-92.

16. Santos UP, Gannam S, Abe JM, et al. Emprego da determinação de monóxido de carbono no ar exalado para a detecção do consumo de tabaco (Use of breath carbon monoxide as an indicator of smoking status). J Pneumol 2001;27:7-12.

17. Deeks JJ, Altman DG. Diagnostic tests: likelihood ratios. BMJ 2004;329:168-9.

18. Javors MA, Hatch JP, Lamb RJ. Cut-off levels for breath carbon monoxide as a marker for cigarette smoking. Addiction 2005;100(2):159-67.

19. Velicer WE, Prochaska JO, Rossi JS, et al. Assessing outcome in smoking cessation studies. Psychol Bul 1992; 11:23-41.

20. Gariti P, Alterman Al, Ehrman R, et al. Detecting smoking following smoking cessation treatment. Drug Alcohol Depend 2002;65:191-6. 